\title{
Water content classification in porous material by periodic forced ventilation
}

\author{
by P. Bison, F. Agrosì, A. Bortolin, G. Cadelano, G. Ferrarini and E. Grinzato
}

ITC-CNR, Corso Stati Uniti 4, 35127 Padova Italy, paolo.bison@itc.cnr.it

\begin{abstract}
A method to analyse thermographic data with periodic temperature variation has been recently proposed. A periodic heat flux is generated on the surface of a moistened specimen by periodically varying the air speed. As a consequence, the evaporation on the surface is enhanced periodically extracting latent heat and producing a temperature variation that is monitored by an IR camera. Two opposite phenomena connected with the water content determine the amplitude and phase of the temperature oscillation: the heat depletion related to effusivity, that dumps the temperature variation and the evaporation rate, that increases the surface cooling. Parameters connected with the water content are evaluated in a set of building materials moistened on the purpose, by using a suitable mathematical model.
\end{abstract}

\section{Introduction}

The application that gives rise to this work is the classification of moisture content in porous materials, mainly used in buildings [1], by IR thermography. It is a matter of fact that the moisture excess highly contributes to the decay of buildings and even more its variability in time. Actually, most of the buildings are affected by such a problem. It is well known that the evaporation process, with the migration of salts within the material, represents the main reason for the deterioration of the surfaces [2]. On the other hand the reliable measurement of water content in porous building materials and especially in-situ is far to be solved with a satisfying technique [3].

The underlying idea for the improved thermographic detection of moisture is that of enhancing the water evaporation from the surface of the material, by means of an increased air speed [4]. In such a way, only the moist surface is cooled and the temperature locally varies on it. A temperature variation should be noticed on the surface of the material with high moisture content, while it should not influence the dry surface, provided that the air that is flowing has the same temperature of the dry material. It is also supposed that a material with different moisture content exhibits a different time response in term of temperature decreasing, with amplitude and time constant as function of the moisture content. In order to better differentiate the experimental forced temperature response, present in any moistened porous material, from that naturally due to the environment, it is planned to submit the material to a continuously modulated ventilation with varying air velocity, from zero to a fixed value (of the order of a few meters per second). The speed is modulated in an approximately sinusoidal way. As a consequence of the ventilation, the surface temperature of the moistened material varies periodically at the period of the forcing ventilation and, at the same time, it decreases in the mean as a consequence of the fact that the stimulus is generating a heat flux (due to the latent heat extraction) with a negative average value [5].

A model has been proposed [6] that describes the effect of evaporation enhancement. It is completely focused on the thermal effects, neglecting the effect of mass transfer that are considered to work in a different time scale with respect to the duration of the experiment. The surface temperature profile is computed by the numerical solution of the 1D Partial Differential Equation:

$$
\frac{{ }^{2} T}{x^{2}} \frac{1}{t}=0
$$

with $x$ the spatial coordinate and $\alpha$ thermal diffusivity. The solution is given in case of a thick slab with boundary condition of prescribed heat flux on one surface (the back of the sample is considered adiabatic) and with varying heat conduction exchange coefficient, results of the varying velocity of air on the surface:

$$
\begin{aligned}
& \left.\frac{T}{x}\right|_{x=0}=0(1+\sin (t)) h_{0}+h_{1}(1+\sin (t)) T \\
& \left.\frac{T}{x}\right|_{x=L}=0
\end{aligned}
$$

Here $\lambda$ is the thermal conductivity of the material, $h_{0}$ is the heat exchange coefficient due to the natural convection and $h_{1}$ is the heat exchange coefficient of the forced convection that is modulated periodically, $L$ is the thickness of the slab [7]. The initial conditions of the sample are of null temperature and the temperature of the environment is null as well. By means of the MATLAB® PDE solver [8], the equation (1) is computed with boundary as in equation (2). The parameters used in the computation are reported in Table 1. In particular the value of $\Phi_{0}$ is based on the value of the Latent Heat of water at $23{ }^{\circ} \mathrm{C}\left(\mathrm{LH}\left(\mathrm{T}=20^{\circ} \mathrm{C}\right) \sim 2.4 \cdot 10^{6} \mathrm{~J} \mathrm{~kg}^{-1}\right)$ and on the Evaporation Rate 
experimentally obtained for a saturated Pietra Serena stone (ER $~ 3.5 \cdot 10^{-5} \mathrm{~kg} \mathrm{~m}^{-2} \mathrm{~s}^{-1}$ ) in an environment with $\mathrm{RH} 45 \%$ and a maximum air speed of $1.5 \mathrm{~m} \mathrm{~s}^{-1}$. Moreover, the thermal parameters of Pietra Serena are computed by suitable weighted mean of those measured for the dry stone and those of water, considering that the saturated stone contains 2 $\%$ of water in weights. The result of the simulation is presented in Fig. 1.

Table 1. Parameters of the simulation

\begin{tabular}{|c|c|c|c|c|c|c|c|c|c|}
\hline \multicolumn{5}{|c|}{ Material: Pietra Serena } & \multicolumn{3}{|c|}{$\begin{array}{c}\text { Boundary conditions } \\
\text { parameters }\end{array}$} & \multicolumn{2}{|c|}{ frequency } \\
\hline $\begin{array}{c}\lambda \\
\mathrm{Wm}^{-1} \mathrm{~K}^{-1}\end{array}$ & $\begin{array}{c}\rho \\
\mathrm{kg} \mathrm{m}^{-3}\end{array}$ & $\underset{\mathrm{J} \mathrm{kg}^{-1} \mathrm{~K}^{-1}}{\mathrm{C}_{\mathrm{p}}}$ & $\begin{array}{c}\alpha \\
m^{2} s^{-1}\end{array}$ & $\begin{array}{l}\mathrm{L} \\
\mathrm{m}\end{array}$ & $\begin{array}{c}\Phi_{0} \\
W^{-2}\end{array}$ & $\begin{array}{c}\mathrm{h}_{0} \\
\mathrm{Wm}^{-2} \mathrm{~K}^{-1}\end{array}$ & $\begin{array}{c}\mathrm{h}_{1} \\
\mathrm{Wm}^{-2} \mathrm{~K}^{-1}\end{array}$ & $\mathrm{f}^{\mathrm{f}}{ }^{-1}$ & $\begin{array}{c}\omega \\
\mathrm{s}^{-1}\end{array}$ \\
\hline 2.45 & 2591 & 877 & $1.1 \cdot 10^{-6}$ & 0.05 & 84 & 5 & 50 & 0.125 & 0.7854 \\
\hline
\end{tabular}

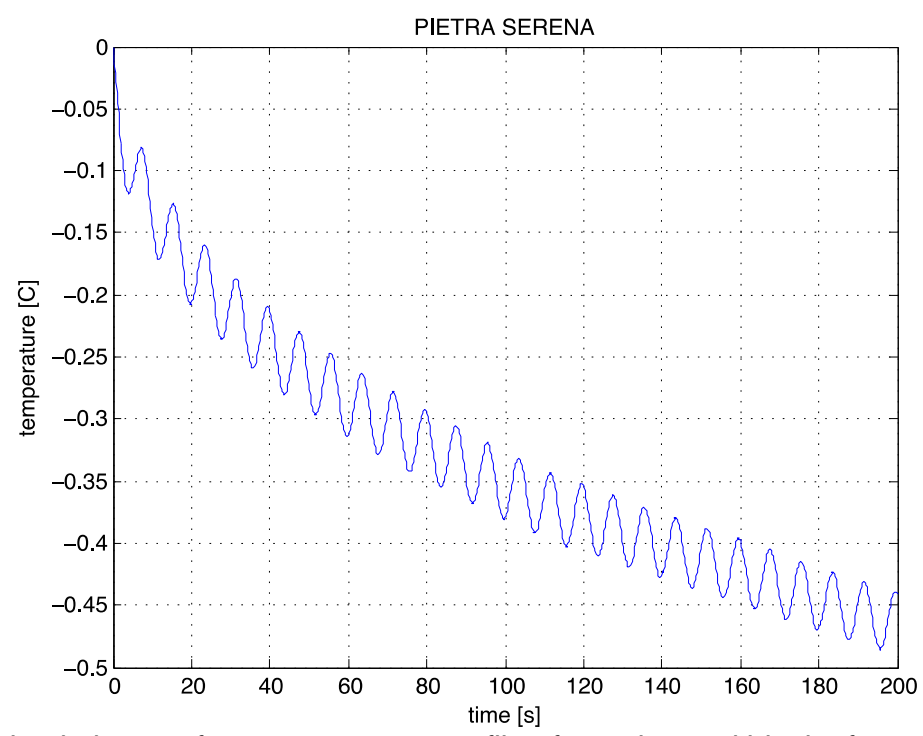

Fig.1. Result of the simulation: surface temperature profile of a moistened block of material. Parameters are reported in Table 1.

The temperature variation is due to main phenomena: effusivity increasing with the water content that dumps the temperature variation and the evaporation rate that is enhanced by the ventilation and increases the temperature variation. Purpose of this paper is that of determine the parameters appearing in equation (1) and (2) by non-linear fitting the experimental data coming from IR camera, with controlled environmental conditions.

\section{REFERENCES}

[1] Grinzato E., Bison P.G., Marinetti S., Vavilov V., "Thermal/Infrared nondestructive evaluation of moisture content in building: theory and experiment", in Proceedings of the international symposium "Dealing With Defects In Building", Varenna (Italy), Eds. M Moroni and P. Sartori, Sept. 1994, Part 1, pp. 345-356, 1994. [2] Massari G., M. Massari M., Damp buildings, old and new, ICCROM Publications, Rome (Italy), 1994. [3] Bison P., Cadelano G., Capineri L., Capitani D., Casellato U., Faroldi P., Grinzato E., Ludwig N., Olmi R., Priori S., Proietti N., Rosina E., Ruggeri R., Sansonetti A., Soroldoni L., Valentini M., "Limits and advantages of different techniques for testing moisture content in masonry", Materials Evaluation, Vol. 69, N 1, pp. 111 116, 2011.

[4] Grinzato E., Cadelano G., Bison P., "Moisture map by IR thermography”, Journal of Modern Optics, Taylor \& Francis, Vol. 57, № 18, pp. 1770-1778, 2010.

[5] Grinzato E., Ludwig N., Cadelano G., Bertucci M., Gargano M., Bison P., "Infrared thermography for moisture detection: a laboratory study and in-situ test", Materials Evaluation, Vol. 69, N 1, pp. 97-104, 2011.

[6] Bison P., Cadelano G., Grinzato E., "Thermographic Signal Reconstruction with periodic temperature variation applied to moisture classification", QIRT Journal, Vol. 8, №. 2, pp. $221-238,2011$.

[7] Carslaw H.S., Jaeger J.C., Conduction of Heat in Solids, Oxford University Press, 1959.

[8] http://www.mathworks.com/ 